\title{
Big Data and Personalized Pricing
}

\author{
Etye Steinberg \\ University of Toronto
}

\begin{abstract}
Technological advances introduce the possibility that, in the future, firms will be able to use big-data analysis to discover and offer consumers their individual reservation price (i.e., the highest price each consumer would be willing to pay, given their preferences and available income). This can generate some interesting benefits, such as a better state of affairs in terms of equality of both welfare and resources, as well as increased social welfare. However, these benefits are countered by considerations of relational equality. This article takes up the market-failures approach as its basis to demonstrate what is wrong with using big data to personalize prices. The article offers an improvement to the market-failures approach and argues that what is wrong with using big data to personalize prices is that it unfairly undermines consumers' ability to benefit from the market, which is the very point of having a market.
\end{abstract}

KEY WORDS: big data, personalized pricing, price discrimination, market-failures approach, consumer fairness, relational equality

$\mathrm{B}$ ig data consists in the mass collection and algorithmic analysis of data regarding individuals through the web. Such data consists of some obvious information, such as one's browsing history, purchase history, social media activity, web routine, and locations visited (e.g., as tracked on one's mobile phone), but also of much more subtle behaviors, such as the amount of time a web page was open in one's browser, the speed at which one moved their mouse pointer, and the time the pointer spent at different parts of the screen and on the webpage (e.g., near the price, around the 'close window' icon, and so on). In the last two decades, firms have become quite good at collecting enormous amounts of data on their consumers, ${ }^{1}$ and they have been able to refine their models and algorithms to a high degree of accuracy. ${ }^{2}$

So far, firms have been profiling consumers and grouping them together according to gender, age, location, search terms, lifestyle, and probable income (given past purchases), to name a few. This allows firms to practice extensive targeted marketing and advertising. It also allows them to estimate each group's likely average reservation price (i.e., the highest price that one would be willing to pay for a product or service, given one's income and preferences), or,

\footnotetext{
${ }^{1}$ Walmart, for instance, collects 2.5 petabytes $(2,500,000$ gigabytes) of data per hour (Marr 2017).

${ }^{2}$ In a notorious case, Target was able to recognize that a teenager was pregnant - and send her relevant coupons and commercials_-before she had known, and before she was able to discuss the matter with her parents (Duhigg 2012).
} 
alternatively, to group together consumers by estimating them as having similar reservation prices, given the data the firm has on these consumers. In this way, firms exercise grouping-based pricing. Now, while there is hopefully still a long way until we get there, it seems theoretically possible that firms' accuracy in grouping, collecting, and analyzing data could become so well-refined that firms will be able to profile consumers with perfect precision and assign them to groups of one member. In other words, it is possible that technological advances in data collection and analysis will allow grouping-based pricing to evolve into personalized pricing.

In personalized pricing, each consumer is charged according to their individual reservation price. Personalized pricing extracts all of one's consumer surplus. For this to happen, the firm needs to have perfect information on the consumer's preferences, utility functions, indifference curves, current mood, values, available income, and so on. This pricing policy will generate the most revenue for the firm. Right now, personalized pricing is likely to incur incredible costs for the firm surrounding the collection and analysis of all this information. Furthermore, consumers are not likely to divulge all of this information. ${ }^{3}$ But the advent of big data has significantly reduced the costs of collecting and analyzing information on each consumer, and has consumers divulging information in ways that are implicit in their habits and behaviors. What could be the ethical status of such a practice? Are there any ethical considerations in favor of it? Might there be anything ethically wrong with big-data driven, personalized pricing (hereafter BDPP)? Is there anything unique to BDPP, for instance, that its ethical aspects are not applicable to the use of big data in general, ${ }^{4}$ or to price discrimination (of which BDPP is just one species)? ${ }^{5}$

\footnotetext{
${ }^{3}$ One case of price discrimination that comes very close to personalized pricing is tuition assistance. When applying for tuition assistance or tuition relief, college applicants provide nearly all the information required for the university administration to figure out how much each applicant is willing to pay. Note, however, that applicants' willingness to disclose all this information can be explained by different factors, some seemingly reasonable (e.g., available income, or caring immensely about getting into college, so much so that one is willing to expose personal details and devote time to working on one's assistance application), others not so much (e.g., framing bias-instead of starting from zero tuition and asking applicants how much more they would be willing to pay, the process sets a high tuition cost as a default and asks applicants how much of a discount would convince them to pay and attend the school).

${ }^{4}$ Privacy, health, and security are some topics that are pertinent to discussions regarding the ethics of big data (for various discussions, see Béranger 2016; Collmann and Matei 2016; Galliott and Reed 2016; Lever 2013; Erwin 2015; Stahl 2016). The discussions there revolve around whether and to what extent consent can allow for invasion of privacy, what privacy might mean, how to balance considerations of privacy with those of, say, national security, and more. For the purposes of this article, it is not necessary to delve into these general ethical concerns with big data. Even if we assume away any such problems, using big data to personalize prices may still be an interesting moral phenomenon in its own right. It is, therefore, worthwhile examining it not as a particular case-study of a broader issue, but rather on its own.

${ }^{5}$ I use the terms 'price discrimination' and 'price differentiation' interchangeably. Nothing hangs on this. The term 'price discrimination' should not be construed as implying ways that discrimination is construed in political contexts (e.g., as practiced against protected classes).
} 
In this article, I argue that there is something uniquely wrong with BDPP: it is inherently unfair towards consumers, undermining their role as participants in the market by making it unreasonably costly to practice their ability to negotiate prices or shop around. This, in turn, makes it impossible for consumers to substantially benefit from taking part in the market, which is (at least part of) the point of having markets in the first place. In what follows, I first discuss the benefits of BDPP, which include a better state of affairs in terms of both equality of welfare and equality of resources, as well as increased overall social welfare (in terms of market efficiency). However, it turns out that BDPP increases relational inequality, i.e., inequality of social status and standing. I then argue that BDPP is ethically wrong in a way that is unique from other forms of price discrimination and other uses of big data. The basis for my view regarding the ethical status of BDPP lies in the Market-Failures Approach (MFA). I assume here, with MFA, that there is something unique within the realm of business that generates special ethical requirements, especially when we consider that the point of having markets is to improve consumers' welfare. I argue that MFA does not fully capture what might be uniquely wrong with BDPP. However, with proper refinement-specifically, focusing on the status of consumers in the market-we can demonstrate how BDPP is ethically wrong in a unique way.

\section{THE BENEFITS OF BDPP}

BDPP is a species of price discrimination. In price discrimination, firms charge individuals different prices for the same (kind of) product with the same (or almost the same) production costs. ${ }^{6}$ For instance, a hardcover edition of a book may be priced much higher than its respective paperback edition, despite their nearly identical production costs. In such cases, often called 'versioning,' or 'second-degree' price discrimination, ${ }^{7}$ the production costs are almost the same, but the pricing does

\footnotetext{
${ }^{6}$ According to Stigler (1987), price discrimination occurs when the ratio between the prices of similar products differs from the ratio between their marginal production costs. More formally, if $\mathrm{P}$ stands for price and $\mathrm{C}$ for marginal cost, and they are indexed by product, then price discrimination exists whenever $P_{l} /$ $C_{1} \neq P_{2} / C_{2}$. While this 'markup' approach is very common, other approaches place emphasis on the absolute difference between prices and between costs (Phlips 1983). With such 'margin' approaches, price discrimination exists whenever $P_{1}-P_{2} \neq C_{1}-C_{2}$. I take up the markup view here, but nothing in my argument hangs heavily on this.

The terminology here is from (Clerides 2004), who argues (a) that the markup and the margin approaches are not exhaustive and produce different verdicts on whether there is price discrimination; and (b) that the best way to discover price discrimination is by focusing not on markup or margin, but rather on the cost of arbitrage, if it were possible. For the purposes of this article, we can put these considerations to one side.

${ }^{7}$ Talking about price discrimination practices in terms of degrees is quite common in the economic literature on the topic and draws on Pigou's pioneering work on the subject (1920). As I understand it, different degrees of price discrimination are meant to track the success of each type of price discrimination in extracting consumer surplus. Nevertheless, I avoid talk of degrees as some may claim that the differences here are not differences of degree, but rather of kind. Nothing crucial hangs on this.
} 
not track production costs (Clerides 2002) ${ }^{8}$ Another kind of price discrimination manifests itself in certain practices, such as discounts for senior citizens, overcharging tourists, or charging women more than men for products that perform the same function (Paquette 2015). These instances are a form of price discrimination called 'grouping,' or 'third-degree' price discrimination. Finally, there is 'personalized' pricing, or 'first-degree' price discrimination. Some forms of personalized pricing include auctions and tuition assistance. In personalized pricing, consumers are priced individually. The firm tries to price consumers as much as they are willing to pay (given their preferences and available income), according to the information the firm has on each and every consumer.

Price discrimination allows firms to extract more consumer surplus (i.e., the difference between how much one is willing to pay and what one ends up paying). Price discrimination is impossible in a perfectly competitive market, ${ }^{9}$ as it relies on (1) there being certain information asymmetries, e.g., the firm needs to be able to sort between different consumers and to know how much each consumer, or group of consumers, is willing to pay, for what kind of product; (2) the firm having sufficient market power, so that it can charge above marginal cost and so that consumers cannot easily switch to suppliers who sell at lower prices (otherwise, consumers could simply purchase from a firm who charged them $\$ 0.01$ less than the personalized-price firm, or a firm that charged $\$ 0.01$ less than that, and so on); and (3) a firm's ability to make arbitrage and reselling impossible, so that consumers who pay less cannot resell to those who would have paid more (Varian 1989, 599). It is, thus, most likely to arise in cases of monopoly or oligopoly (Varian 1989).

BDPP can generate some ethically significant social benefits. A market with BDPP can lead to a more equal distribution of welfare and resources than a market without BDPP. Such a market can also lead to an increase in overall social welfare (in terms of market efficiency). These benefits make for a strong case in favor of the moral permissibility of BDPP. I discuss these benefits below.

\footnotetext{
${ }^{8}$ In versioning, we should not think of the different versions of the same product as different products altogether. A plane ticket is a different product than a bus ticket; but two tickets for the same flight purchased through the same retailer are the same product, whether or not one ticket is also, say, fully refundable.

Historically, this has also been the way economists have treated different seating classes. This is because economy class, economy plus, and business class offer seats on the same flight, and their prices do not track cost: there is hardly any difference between the marginal production cost of a seat in business class and a seat in economy. In an often-quoted passage discussing the extremely different conditions of third-class, second-class, and first-class rail tickets in nineteenth-century France, Jules Dupuit once wrote:

It is not because of the few thousand francs which would have to be spent to put a roof over the third-class carriages or to upholster the third-class seats that some company or other has open carriages with wooden benches. What the company is trying to do is to prevent the passengers who can pay the second-class fare from traveling third class; it hits the poor, not because it wants to hurt them, but to frighten the rich (Ekelund 1970, 275).

${ }^{9}$ Indeed, the first systematic discussions on the economy of price discrimination were embedded in works that focused on imperfect competition (Pigou 1920; Robinson 1933). An interesting exception to this is the versioning practiced by airlines, which is actually sustainable (and, perhaps, even necessary for survival) in a competitive market (Levine 2002; Stole 2007). Given that the article focuses on personalized pricing, we can overlook this instance.
} 


\subsection{Equality}

The thought that BDPP can reduce inequalities may seem surprising, at least at first glance. BDPP allows firms to price people unequally. The thought that we could treat people equally by pricing them unequally seems odd. How then, one might ask, could BDPP allow us to treat people equally? There are many ways to treat people equally, and many different things we might want to equalize in society. We might want to equalize welfare (Dworkin 1981a), or resources (Dworkin 1981b), or capabilities (Sen 1980), or access to opportunities (Cohen 1989; Arneson 1989), or regard, social standing, and status (Anderson 1999). The kinds of equality that are most relevant to BDPP are equality of welfare, equality of resources, and (as I discuss in sections 2 and 4 ) equality of social standing. The upshot of this section is that while pricing everyone equally (i.e., charging everyone the same price) is one way of treating everyone equally, it also seems to undermine other ways of treating people equally, specifically in terms of welfare and resources. ${ }^{10}$

First, personalized pricing reduces welfare inequalities. When consumers pay their reservation price, they get, in return, the exact amount of welfare that this monetary sum was worth for them. This appears to correct for a seeming inequality in treatment that is inherent in the basic price mechanism (i.e., without BDPP). Suppose that Bill can and is willing to pay more than the market price for a product (e.g., a gallon of milk). With equal pricing, Bill pays the market price and gains greater welfare than, say, Alex, who cannot or is not willing to pay more than the market price. Bill now has a surplus that he can use for other purposes; Alex does not. So, by purchasing an item at an equal price, those individuals with higher reservation prices will end up better off than those consumers who cannot pay above the market price.

It follows that equal pricing (i.e., charging different consumers the same price) does not treat consumers equally in terms of welfare. Charging consumers their reservation price seems like a better way of treating their welfare equally: each consumer ends up paying as much as the product is worth to them (in terms of welfare, translated into money). If Bill values a gallon of milk more than Alex does (or, alternatively, if Bill values money less than Alex does), then treating them equally in terms of welfare seems to require that we do not offer them the same price. Rather, if we want to equalize welfare, then it seems that charging Bill more than Alex is the way to go. And BDPP gets us there.

Second, and relatedly, personalized pricing leads to a more equal distribution of resources. When Alex and Bill pay their respective reservation prices for the same product (e.g., a gallon of milk), this reduces inequality of resources: Bill does not get to accumulate as much resources as he would have under equal pricing. In regular pricing, those with more resources pay a smaller percentage of their income for the same product than those with less resources do.

BDPP leads the wealthier to pay a higher percentage of their resources for the same product than without BDPP. Of course, those with less resources may also end up paying a higher percentage than they otherwise would have. However, the less resources

${ }^{10}$ The argument here develops insights in Marcoux (2006). 
they have, the more likely it is that they were already paying somewhere around their reservation price before we introduced the possibility of BDPP. With BDPP, the more resources one has, the higher the price they are charged. Because it charges the wealthier more than equal pricing does, BDPP makes accumulating resources more difficult. ${ }^{11}$ And when all participants in the market pay personalized pricing for everything, then it is likely to become even more difficult. And as accumulating resources becomes more difficult, resources end up being distributed more equally. BDPP, thus, seems like a better option for treating people equally in terms of resources. ${ }^{12}$

Again, we see that there is something about equal pricing that does not treat consumers equally. So, treating people with price equality violates welfare and resource equality. Trying to achieve those kinds of equality will require not treating people equally in terms of charging them the exact same prices. Achieving equality of welfare and equality of resources (through the mechanism of the market) requires charging different consumers different prices.

\subsection{Social Welfare and Efficiency}

Finally, as economists have historically pointed out, price discrimination (of which BDPP is one subspecies) can increase overall social welfare by serving more consumers than a similarly imperfect market without price discrimination. ${ }^{13}$ When firms price discriminate, they can serve consumers who cannot afford the (not perfectly competitive) equilibrium price by charging them a lower price. Firms can then compensate for this by charging those consumers who can afford to pay more higher prices. We see such positive effects in common practices of grouping, or third-degree price discrimination, that do not seem to elicit any moral uproar-for example, senior-citizen discounts for museums or public transit and tuition waivers or assistance funds (indeed, in the latter, we come very close to personalized pricing). In such cases, there seems to be nothing wrong, or at least nothing that warrants any moral indignation.

We can reach similar results with personalized pricing. Suppose that the would-be imperfectly competitive equilibrium price of a gallon of milk is $\$ 5$. If Bill's reservation price is $\$ 20$ and Alex's is only $\$ 4$, then only Bill will purchase the milk (and retain a $\$ 15$ surplus), and Chris (the supplier) will only make $\$ 5$ in revenue. But, if Chris has the resources and is permitted to personalize prices, then both Bill and Alex will be able to purchase the milk (each at their personal reservation price), and Chris will make $\$ 24$ in total revenue. This seems to allocate resources much more efficiently, increase total product and welfare, and include in the market previously underserved groups (namely, Alex).

\footnotetext{
${ }^{11}$ The market we are envisioning here is a BDPP market. This means that even those who hold shares in firms practicing BDPP and make a profit from this practice still have to pay their own personalized prices once they go to purchase anything (including shares in BDPP-practicing firms).

${ }^{12}$ Of course, one may claim that in both the welfare and the resource cases, we reduce inequality by 'levelling down'-i.e., by making those that were better off worse, and not by making those that were worse off better-but if we consider things strictly from the point of view of equality of welfare and resources, BDPP seems to make things better.

${ }^{13}$ See, for example, Pigou (1920), Robinson (1933), and Varian (1985), as well as a more contemporary analysis in Elegido (2011) and Odlyzko (2004).
} 
To see how price personalization, in general, can lead to greater product access for previously underserved consumers, it is helpful to put things into more formal economic terms. Recall that one of the conditions for price discrimination, in general, is that the price discriminating firm has significant market power. For convenience, let us suppose that the price-personalizing firm is a monopoly. ${ }^{14}$ So, we are dealing here with an imperfect market with a monopoly. For a monopoly, maximum profit is achieved when marginal revenue (MR) equals marginal production cost (MC). In a market without personalized pricing, MR has a steeper downward slope than the aggregate demand function (D), because the revenue from one more unit sold has a backward effect that decreases the revenue from previously sold units. ${ }^{15}$ In a perfectly competitive market, production occurs at the equilibrium between $\mathrm{D}$ and MC. This means that in the case of a monopoly that does not personalize prices, the quantity of product sold is smaller than the quantity that would have been sold in a competitive market, and the monopoly price is higher than that set in a competitive market.

However, a price-personalizing monopoly will produce the same quantity as that produced by a perfectly competitive market. For a price-personalizing monopoly, $\mathrm{MR}=\mathrm{D}$, because the revenue from one additional unit does not carry back to revenue from previous units. ${ }^{16}$ And since production is set at $\mathrm{MR}=\mathrm{MC}$ for a monopoly, it follows that for a price-personalizing monopoly, production will be set at $\mathrm{D}=\mathrm{MC}$, i.e., at the same quantity that a perfectly competitive market would have produced. Personalizing prices will allow this monopoly to produce as much as a competitive market would have produced, and to price the last produced unit at the would-be competitive equilibrium price.

The general point here is that price personalization makes it possible for an imperfect market to serve all the consumers that would have been served in a perfectly competitive market; it's just that each consumer would pay as much as they are willing to pay, and not a penny less. ${ }^{17}$

In addition, as Elegido (2011) reminds us, the fact that people have given their consent to purchase a certain product at a certain price is evidence that this was worthwhile for them (from their own point of view). In the example above, Bill purchases a gallon of milk for $\$ 20$, and Alex for $\$ 4$. It seems fair to assume that

\footnotetext{
${ }^{14}$ The analysis here is for the case of a monopoly, but similar analyses with the same results can be made in the case of price-personalizing oligopolies (Varian 1989).

${ }^{15}$ Suppose the aggregate demanded price for one unit is $\mathrm{p}_{\mathrm{q} 1}$, and for two units $\mathrm{p}_{\mathrm{q} 2}$, which is smaller than $\mathrm{p}_{\mathrm{q} 1}$. Let $\delta \mathrm{P}_{\mathrm{ij}}$ stand for the difference between $\mathrm{p}_{\mathrm{i}}$ and $\mathrm{p}_{\mathrm{j}}$. Since there is no price discrimination, a monopoly selling two units would make a total of $2 * \mathrm{p}_{\mathrm{q} 2}$, which is equal to $2 *\left(\mathrm{p}_{\mathrm{q} 1}-\delta \mathrm{P}_{12}\right)$, which leads to $\mathrm{MR}=2 \mathrm{p}_{\mathrm{q} 1}-2 \delta \mathrm{P}_{12}$. The demand curve at two units, however, is $\mathrm{D}=2 \mathrm{p}_{\mathrm{q} 1}-\delta \mathrm{P}_{12}$. Thus, we see that $\mathrm{MR}$ has a steeper slope than D.

${ }^{16}$ Consider altering the case in the previous note to that of a price-personalizing monopoly. There, we supposed that the aggregate demanded price for one unit is $\mathrm{p}_{\mathrm{q} 1}$, and for two units $\mathrm{p}_{\mathrm{q} 2}$, which is smaller than $\mathrm{p}_{\mathrm{q} 1}$. But now, when a monopoly performs perfect price personalization, it can sell the second unit at $\mathrm{p}_{\mathrm{q} 2}$ while also selling the first unit at $\mathrm{p}_{\mathrm{q} 1}$. Thus, the marginal revenue for a price-personalizing monopoly is equal to the demand, or MR=D.

${ }^{17}$ Recall that 'willingness' is understood here as a technical term, signifying the highest monetary value one assigns to a good, given one's available income and preferences.
} 
this was a worthwhile purchase for Bill — as far as Bill was concerned (given his income, preferences, the cost of waiting for a better deal, and so on). ${ }^{18}$ And, if Bill considered this a worthwhile deal, then it seems (a) that things are better overall; and (b) that Bill does not have a claim against Alex getting a better deal.

To see why, compare this with the case of time-limited deals: if Bill had just missed a $\$ 4$ deal (which Alex was able to get just in time) and decided to go ahead and pay $\$ 20$, then it seems that Bill was willing to pay $\$ 20$. Prima facie, there seems to be nothing morally wrong in this case. If so, then we reach the following conclusion: even though Bill did not get as good a deal as Alex did, there is nothing wrong with not getting a better deal than someone else. Therefore, there is nothing wrong with Bill being priced $\$ 20$ rather than $\$ 4 .{ }^{19}$ In the case above, everyone gets the product they want at a price they are willing to pay. Thus, we get the benefit of increased market efficiency: everyone is better off now, without harm to anyone. It seems that this may be another case where markets improve overall social welfare.

In addition, there is a general point to be made here: we may say that the market consists of a constant struggle over consumer surplus. Sometimes consumers get more, sometimes firms get more. ${ }^{20}$ What is important is that there is no need to assume that consumers have any moral right to get a good deal. Prices fluctuate all the time; and, so long as the terms and conditions of the competition between consumers and firms over consumer surplus are fair, that's fine. Of course, this raises the question: are these terms and conditions fair? Below (in section 4) I argue that they are not.

\section{BENEFICENCE, TRANSPARENCY, AND RELATIONAL EQUALITY}

In 2000, it was revealed that Amazon had bundled together different DVDs, and that it had sold these bundled products to different customers at different prices. Amazon used data on its customers in order to group them and offer different prices to members of different groups. In addition, it seems that Amazon did this merely

\footnotetext{
${ }^{18}$ Marcoux (2006) uses a similar line of reasoning to argue for the permissibility of price discrimination in terms of treating people equally (as discussed in section 1). Compare with Nozick's example of basketball fans who pay extra to watch a famous player play (Nozick 1974, 160-64). In general, we can see that Marcoux's and Elegido's strategy here is similar to Nozick's, in the sense that they all focus on the moral significance of respecting people's autonomous decisions over other considerations. Thanks to Chris MacDonald, for pointing out this similarity.

${ }^{19}$ This discussion makes two naïve assumptions: First, that comparison and envy do not play a role in preference satisfaction. Second, that from a moral point of view, comparison and envy should not play a role in preference satisfaction. These assumptions are not intuitive and would normally require a lot of argumentation to support them. However, it is safe to rely on these assumptions here, since even if we hold on to them, the reply in the following sections will still work.

In addition, Elegido argues that to complain that Alex received the discount and Bill did not is like complaining that Chris (the shop owner) decided to give Alex (and not Bill) a gift of \$16, and that there seems to be nothing here that is unfair or unjust $(2011,650)$. Note, however, that this way of putting things seems to violate equal treatment. Specifically, if Chris, as shop owner, gives Alex a \$16 discount (rather than, say, Chris opening up her wallet and gifting Alex personally, as a friend), then it seems that Alex has been awarded preferential treatment. In the amended example I have used here, we avoid this problem.

${ }^{20}$ Thanks to Waheed Hussain for putting things this way for me.
} 
for profit and for no other socially beneficial purpose. This is a rather clear case of using big data to price people according to groupings. The public response at this discovery was predictably negative and disapproving (Krugman 2000). But is there really anything wrong with this case? We have just seen how price discrimination in general, and BDPP in particular, can generate ethically-significant, positive outcomes.

In this section, I argue that certain considerations can undermine these positive outcomes of BDPP. First, I argue that the increase in social welfare can be countered by what I term here 'the beneficence condition,' according to which there is something wrong with BDPP when it does not contribute to a socially desirable end in a way that consumers can track so that they can tell what this end is and whether BDPP contributed to it. Second, I argue that the improvements to equality of welfare and resources are countered by considerations of relational equality, i.e., equality of social status and standing. The conclusion to draw from this section is that while there are considerations in favor of BDPP, there are also considerations against it, and it is not clear how the weight of these considerations tilts the moral scales.

\subsection{The Beneficence Condition}

Some may argue that BDPP is justified only and insofar as it generates a socially desired benefit that consumers can track. ${ }^{21}$ I call this the 'beneficence condition.' BDPP, in such cases, generates a desired social outcome, and everyone can track this benefit: everyone knows who BDPP benefits, why it benefits them, and how others may also enjoy it. For example, senior-citizen transit discounts are meant to address the fact that there is more poverty amongst the elderly, and that the elderly do not have as much available income as other groups in society $\mathrm{do}^{22}$ In this and similar cases, price discrimination works to increase some social 'good' and is not used as an instrument for mere profit maximization: senior citizens, who normally have less available income, can more easily afford riding public transit. ${ }^{23}$ Without the social benefit, price discrimination is likely to elicit an indignant public response. If price discrimination does not achieve socially desired or beneficial outcomes, then the beneficence condition is unsatisfied, and price discrimination is likely to ensue in justified public criticism.

Moreover, if these socially beneficial outcomes are simply a happy coincidence, an unintended by-product of a strategy that only maximizes profit, then this also justifies indignation: it is reasonable for consumers to want to know whether and how they benefit from certain market practices. In this sense, we may claim that

\footnotetext{
${ }^{21}$ See Ezrachi and Stucke $(2016,122)$. While Ezrachi and Stucke focus on these conditions as elements that explain or contribute to social acceptance of price discrimination, my focus here is on whether these conditions justify such acceptance of price discrimination.

${ }^{22}$ Of course, I have assumed away any problems pertaining to framing: if we did not have seniorcitizens discounts, but instead adult-citizen surcharges, we would likely not be perfectly content with the different pricing (Thaler 1999). In general, I ignore any 'framing' effects here, if only because, when reflecting on the matter, consumers do not normally consider these to be valid reasons for making a choice.

${ }^{23}$ Note that with BDPP we can fully satisfy the purpose of the benefit: since not all seniors are financially strapped and, indeed, many may be much better off than non-seniors in poverty, personalized pricing allows us to charge more from those who can afford it, so that we can charge less from those who cannot.
} 
there is a transparency requirement in service of the beneficence condition. If we had learnt that some consumers had received a better price than we did, we would want to know why. If there is no good reason, or if suppliers refuse to disclose their reasons, then this would seem suspicious. We would likely, and justifiably, want to know what is special about these customers who paid lower prices. Are the firms practicing nepotism? Is there any discrimination here against protected classes? Is there anything we can do to switch over to that group and also get a better price? And so on. Without transparency, price discrimination appears completely arbitrary, to the point that it doesn't seem to contribute to any kind of social benefit.

Consider: in the case of senior-citizen discounts, everything is above board, and the reasons for differential pricing, as well as the criteria for receiving the discounts, are available to everyone. Even in the case of, say, group discounts or amount discounts, the price differentiation is transparent, which contributes to acceptance of the practice. In particular, transparency serves to satisfy the beneficence condition, which requires that consumers should be able to track the social benefit in question.

What we have here, then, is a condition or restriction on the moral permissibility of BDPP: without transparency, we cannot tell whether BDPP contributes to some social benefit. We, therefore, lack the ability to track any social benefit BDPP might produce. And, without the ability to track any social benefit, it would be reasonable to believe that a firm practicing BDPP is doing so for profit alone and for no other reason. The main point here is that transparency is important for justifying BDPP, because without it we have no way of knowing whether or how this practice will have socially desirable effects, nor do we have any way of knowing whether the firm could be using BDPP for mere profit seeking, or perhaps even for plain old discrimination (e.g., of protected classes).

This does not demonstrate that the benefits of BDPP discussed in the previous section are completely undermined by lack of transparency, or by BDPP not serving a socially desired benefit. But it does provide some counterweight against the benefits of BDPP. Recall the Amazon case: there was no transparency and no detectable social benefit. If the beneficence condition holds, then there was at least something wrong with Amazon's conduct in this case.

\subsection{Relational Equality}

Earlier, we compared BDPP and time-limited offer versions of price discrimination. In both cases, Alex paid $\$ 4$ for a gallon of milk, and Bill paid \$20. In the BDPP case, the different pricing was the result of Chris using big data to find out each consumer's reservation price and charging them that price. In the time-limited offer case, Alex and Bill paid different prices because Alex purchased the milk in time to get the better deal, while Bill missed the deadline for the offer and had to pay full price. However, there are two important differences between the BDPP case and the time-limited offer case. First, there is transparency in the latter case. Bill knows why he must pay $\$ 20$ if he is to purchase the milk: he missed the deadline for the $\$ 4$ deal. Second, and relatedly, the time-limited offer is not a case of personalized pricing (and so not a case of BDPP). 
These differences highlight two important points. First, we see that transparency can play an important role in justifying some forms of price discrimination, regardless of any socially desired benefit that such pricing generates (if at all). In particular, it seems to help justify certain forms of 'grouping' and probably 'versioning.' In the time-limited offer case, price discrimination has no detectable social benefit. Thus, the beneficence condition might not hold for all forms of price discrimination.

Second, and in direct response to the arguments for BDPP, transparency will not help justify BDPP. In fact, if the firm using BDPP were transparent, this would help demonstrate what might be wrong with BDPP. To see why, suppose Bill receives this message while shopping online:

Dear Bill, according to our calculations, your reservation price for this bundle of DVDs is $\$ 40$. Thus, we are pricing it at $\$ 40$ for you. Other consumers will pay different prices, given their different reservation prices. (Do you know Alex? Her reservation price is $\$ 16$, which is what she will have to pay, if she decides to buy these DVDs from us.)

We can also think of Alex receiving a similar message, mentioning that since she is more price-sensitive than Bill, or has less money than Bill, she will be charged less.

The tone in these messages is similar to the tone found in messages that Elizabeth Anderson imagines one might receive in a society with egalitarian distributive justice $(1999,305)$. There, Anderson envisions how an egalitarian society might distribute resources to those who suffer from bad "brute luck"24 — those who, through no fault of their own, are, e.g., untalented or disabled. These individuals would be informed that, unfortunately, they are not as able as other luckier individuals to succeed in accumulating resources in this imaginary society. Therefore, the state will compensate them appropriately. This, according to Anderson, is insulting and belittling. Now, while an egalitarian need not commit herself to this particular method of redistribution, there is a deeper point that Anderson illuminates here: it may be that distributive equality undermines relational equality (or as Anderson terms it, democratic equality), i.e., equality in social status and standing.

The messages that Bill and Alex would hypothetically receive from a firm practicing BDPP demonstrate that the firm does not treat them as equals in terms of their standing and social status as participants in the market with regards to each other, as well as with regards to the firm using BDPP. This is true even if we rephrase the messages to sound more positive (e.g., "Congratulations, Bill—you're rich! Here's your price. It's kind of high, we know, but you can totally afford it!" or "Alex, we know money is a bit tight right now, so you get a lower price than others.").

But what does 'having equal status as participants in the market' mean? I think that the most helpful way to think about this is by considering the notion of competition. Consumers usually, hopefully, are not in competition with one another over product or price. We all know that we are going to pay the same prices for the same products at the same time in the same place. Sure, there may be a time-limited offer, or an amount discount, but these are open to all consumers equally. This is true of other

\footnotetext{
${ }^{24}$ As discussed most prominently in Dworkin (1981b) and Cohen (1989).
} 
forms of price discrimination as well: senior-citizen discounts or student discounts are equally open to anyone who qualifies for them. One notable exception to this is auctioning and bidding. In bidding wars, consumers do compete with one another over product and price. This is an especially important exception, since it is a form of personalized pricing. Still, even this competition can be good or bad; it can have or lack fair terms and conditions. Some auctions can be genuine, while others are rigged, for instance. I believe that the lesson to draw here is that for consumers to have equal status with one another in the market, consumers have to (a) have the market equally available to them, so that they do not have to compete with each other over price or product; or (b) if such a competition between consumers is necessary, have the ability to participate in such a competition on fair terms.

The notion of competition can also help us make sense of consumers enjoying equal status in the market with firms. Here, recall the closing statements from the previous section: consumers and firms compete for consumer surplus; what is important is that this competition is fair. Thus, we may say that consumers and firms enjoy equal status in the market to the extent that they can compete for resources and prices on fair terms and conditions. Sure, the average consumer may not be able to haggle with a large firm about its prices; but if she can purchase a similar product somewhere else at a better price, then that's a useful way for her to compete with the firm. In other words, consumers can compete with firms when firms need to compete over consumers.

In using BDPP, a firm does not treat its consumers as enjoying equal status with one another (as participants in the market). This is because BDPP treats consumers in a way that closes off the market to them, so that now consumers do not have equal access to the market. In this sense, consumers become competitors with one another. In addition, the use of BDPP undermines consumers' ability to participate in this competition on fair terms. Such fair terms-for personalized pricing, in particular-would include the option to have a say in how high of a price one is willing to pay. BDPP takes that option away from consumers. In addition, BDPP undermines the equal status we might hope to see between consumers and firms. This is because when firms use BDPP, consumers do not have the ability to go somewhere else where they can pay a non-BDPP price. Firms using BDPP do not compete for consumers and do not need to do so; therefore, consumers cannot compete with firms who use BDPP.

We see, therefore, that BDPP requires treating consumers in a way that undermines their supposed equal standing in the market. Of course, this still does not show why or that extracting consumer surplus is itself somehow morally wrong; auctions seem fine from a moral standpoint. However, recall that we are not concerned with personalized pricing in general, but rather with BDPP. Using auctions to personalize prices and using big data to personalize prices may not be on the same moral footing. ${ }^{25}$

\footnotetext{
${ }^{25}$ For an argument based on relational equality pertaining to the limits of executive compensation, see Néron (2015).
} 
This, together with the beneficence condition, serves to counterbalance the supposed benefits of BDPP. First, recall that BDPP was supposed to have the benefit of improving resource equality and welfare equality. The point there was that treating people as equals in terms of resources requires not treating them as equals in terms of the prices that they get charged. But now we have turned the tables against BDPP: if we ignore the relational aspect of equality, then this undermines the value of distributive equality, whether in welfare or in resources. Furthermore, if BDPP does not produce transparent, socially desired benefits, then this counts (though not decisively) against its moral permissibility.

Second, recall that BDPP carries the promise of increased overall social welfare. However, the discussion of relational equality raises concerns about who would enjoy these benefits. Once we look at things from the perspective of relational egalitarianism, we see that it is possible for different individuals to have different standing in the market (because they have higher reservation prices). Moreover, and more pressingly, BDPP undermines the status of consumers in the market for the sake of increasing the status and standing of firms. Without BDPP, pricing depends on production costs (and where MC meets D). When pricing depends on production costs, firms end up pricing their products as low as possible to meet demand, which allows for a consumer surplus. But, with BDPP, all consumer surplus is lost to firms. This means that BDPP minimizes the benefit consumers could gain from participation in the market (more on this in section 4 below).

\section{THE MARKET FAILURES APPROACH}

We started out discussing the possible benefits of BDPP. Then we saw that BDPP may also have some downsides. Now, we are left weighing the pros and cons of BDPP. This can lead to a battle of intuitions — which would be unhelpful—or could just leave us agnostic. In the following sections, I argue that we should not be agnostic: BDPP is ethically wrong, in a unique way. To demonstrate this, I rely on the market failures approach (MFA). We have seen that, in general, price discrimination relies on a combination of certain market failures (e.g., significant market power, information asymmetry). It would therefore be useful to consider the ethical status of price discrimination — and specifically BDPP — through the lens of MFA.

\subsection{MFA: BDPP Is Wrong}

According to MFA, most notably developed by Heath (2014), ${ }^{26}$ managers are morally constrained by the point of having competitive markets, which is how they lead to a Pareto efficient distribution of resources and benefits (i.e., no one's welfare can be improved without harming someone else). That, says Heath, is what makes markets valuable in the first place. One problem that MFA faces stems from the fact that the conditions for perfect competition are a set of idealizations that are not satisfied in the

\footnotetext{
${ }^{26}$ I focus here on Heath's view at its most recent formulation (2014). See Heath (2004; 2006) for an earlier formulation. For other formulations of this view, see Brown (2013) and Norman (2011).
} 
real world. ${ }^{27}$ Thus, firms have plenty of opportunities to increase profits by exploiting market imperfections. As a result, real markets that are not perfectly competitive fail to produce Pareto-efficient outcomes. According to Heath, this teaches us that managers are morally required to avoid strategies and practices that exploit market imperfections because this undermines efficiency, which is what makes competitive markets valuable in the first place.

The MFA approach seems rather promising in analyzing the moral status of BDPP. Price discrimination is available to firms only under imperfect conditions. Under perfect conditions, if a firm tries to price discriminate, market forces will drive prices back to marginal production cost: when the conditions for perfect competition are obtained, no firm has sufficient market power to set prices or quantities, and there is full, symmetric knowledge of costs and prices. Consumers will switch over to purchasing from those firms that price products at lower prices than those set by the personalized-price firm. ${ }^{28}$

It seems that, from an MFA point of view, BDPP is unethical. Most notably, it exploits and exacerbates the information asymmetries that already exist in the market. Firms do not only have better knowledge of their production costs, but with the advent of big data, they may also know each consumer's reservation price. In this sense, firms that use BDPP do not treat prices as exogenous-they are no longer price takers, as they should be (if they are to be regarded as behaving ethically by MFA). In particular, firms using BDPP do not need the price mechanism to discover consumer preferences and reservation prices; rather, they go into the market already knowing this information. Firms, thus, switch from being price takers to being all-encompassing price setters. From the point of view of MFA, this seems ethically worse than a nondiscriminatory monopoly, as well as non-BDPP forms of price discrimination. After all, the point of having a competitive market is (partly) that firms compete over consumer surplus, and in so competing end up minimizing their profits and maximizing that of consumers. Therefore, the MFA proponent will claim, BDPP is an unethical business practice.

\subsection{Objection: There Is No MFA Problem}

Unfortunately, things are not actually so straightforward. For one thing, recall that according to how Heath currently conceives of MFA, we should focus more on how a certain practice influences market efficiency. Imperfect markets may become more efficient when certain market failures are exacerbated, or when other imperfections are added into the mix; in fact, reducing (but not eliminating) market imperfection may reduce market efficiency ${ }^{29}$ So, it's not entirely clear where MFA

\footnotetext{
${ }^{27}$ These include, for instance, full information about the entire market, for all participants in the market (e.g., consumers and suppliers), participants taking prices as given, and no externalities.

${ }^{28}$ In this sense, Marcoux's (2006) argument about the ephemeral nature of price discrimination is somewhat misguided, as it seems to rely on the assumption that the market is competitive.

${ }^{29}$ This is, in very broad terms, the main point from Lipsey and Lancaster (1956). Of course, this raises a question about whether MFA imposes consequentialist (i.e., efficiency-based) or deontological (i.e., perfect competition-based) constraints on the practices of firms. For recent discussions, see Moriarty (2019) and Steinberg (2017).
} 
stands regarding BDPP. Furthermore, even if we maintained that MFA did prescribe a clear verdict deeming BDPP unethical, it is not clear that such a verdict would be justified on MFA's grounds.

MFA will have a problem giving a clear verdict about BDPP because BDPP allows firms with market power to produce more than they would have otherwise. To see why, recall the discussion earlier (in section 1.2). There, we saw that a price-personalizing monopoly will produce the same quantity that a perfectly competitive market would have produced. The upshot is that BDPP allows market-powerful firms to reach more consumers than they would have reached otherwise. Thus, we see that exacerbating and exploiting market failures (i.e., market power and information asymmetry) end up increasing the overall welfare and efficiency in an imperfect market with price-personalizing firms.

More generally, MFA faces a choice between focusing on market failures and focusing on market Pareto-efficiency. If MFA focuses on market failures, then it can show what's wrong with price discriminating strategies employed by market-powerful firms. However, there are reasons to avoid focusing on market failures as such (Norman 2011; von Kriegstein 2016). If MFA focuses on efficiency instead, then it is more likely to condone rather than condemn BDPP: as we have seen, there are strong economic arguments demonstrating how, in an imperfect market, price discrimination, in general, increases efficiency and total aggregate welfare. In addition, it is not clear if MFA condemns practices that would undermine efficiency in a perfectly competitive market, or practices that undermine efficiency in an imperfect market. In the next section, I offer an alternative formulation of MFA that remains faithful to its main spirit and helps capture what is uniquely wrong with BDPP.

\section{FAIRNESS}

MFA has taken us in the right direction. By drawing our attention to the market imperfections and failures implicated in BDPP, MFA has highlighted two important points. The first point is that BDPP turns firms from price takers into price setters. The second point is that there is an information asymmetry that allows for and is exacerbated by BDPP. It would be useful to expand on these points. In doing so, it will become apparent that the problem posed by BDPP is that it creates an unfair and unreasonable burden on consumers.

The scenario we are dealing with here is one where consumers lose their already limited market power. Specifically, their choices are reduced to all-or-nothing: they can either pay their reservation price, or not purchase the product at all. Consumers cannot 'shop around,' since even if we are not dealing with a monopoly but rather an oligopoly, other firms in this situation also use BDPP. These other firms also price products at each consumer's reservation price.

At this point, one could interject and claim that the competitive market forces should drive down the prices (Marcoux 2006). This claim should be rejected. Recall that this is not a competitive market; otherwise, price discrimination would not be possible. This already gives us reason to suspect that competition will not drive prices down. More importantly, given the imperfect nature of this market, each supplier is 
strongly incentivized to continue personalizing prices according to each consumer's reservation price. The risk of lost profit in the face of price-personalizing competition seems likely to outweigh the competitive market forces that are supposed to drive down the market price. In effect, there is no market price - there are only personalized prices to choose. Profit-maximizing firms will not have an incentive to lower their prices or to charge less than a consumer's reservation price, since charging less than reservation price will lead to a decrease in profits; and, given that we are dealing with an imperfect market where price-personalizing firms have significant market power, it seems that pricing below each consumer's reservation price is unlikely.

Note that even if we assume variation between firms and between product quality, we still reach the same result. Suppose that consumers' reservation prices vary according to brand, product quality, and so on. Consumers may then still be able to shop around for different quality products, produced and sold by different firms. However, these variations are easily reduced to aspects of consumers' preferences. Therefore, products of different brands and quality will be priced differently, but still according to each consumer's relevant reservation price for each product. In this sense, consumers will still not be able to shop around: if consumers are to purchase at all, they will have no choice but to purchase at their reservation price.

I believe that this situation is unfair to consumers, as the ability to shop around and, thus, negotiate prices is what allows consumers to participate in the market and potentially benefit from it. ${ }^{30}$ To see why, it is useful to rely on the guiding rationale of MFA and consider what the 'point' of having a market might be, i.e., what might be beneficial about having a market. One reason to think that it is beneficial and desirable to have a market at all is that a market allows everyone to benefit from its existence and activity. Now, some of this benefit consists of being able to satisfy one's preferences: merely having money is no good by itself; we want to use that money to acquire the things we find important to living our lives well. Some things would probably be harder to come by without the existence of a market; different individuals or communities would have to be entirely self-sufficient. However, once there is a market in place, different individuals can enjoy the fruits of others' labor (and the relative advantages different individuals have) through trade. In turn, one could argue that BDPP does not necessarily reduce one's welfare regarding this aspect of the benefits the market has to offer. After all, everyone gets what they want, and no one pays any more than they are willing to pay. This still allows consumers to have access to goods and services they could not otherwise.

Still, this is not the entire story of what justifies having a market. Another important supposed benefit, which justifies instituting a market to begin with, is that a competitive market provides individuals with the possibility of improving rather than merely maintaining their welfare. Ideally, markets should allow individuals to go beyond mere sustenance and explore new activities and sources of satisfaction. The competition over consumer surplus provides individual consumers with a

\footnotetext{
${ }^{30}$ This is not to say that consumers are not price takers; negotiating, haggling, and shopping around are all plausible parts of being a price taker. When one haggles, one decides to accept the final price given; one does not decide in advance, for the shopkeeper, what that final offer will be.
} 
means of retaining some surplus and using it to acquire and cultivate new interests and develop new preferences. Markets allow for personal growth, but only if they allow consumers to substantially benefit (or 'make a profit,' so to speak) from the market-i.e., retain consumer surplus.

Some may argue that this goes a bit too far; individuals benefit from the market by being able to satisfy desires they otherwise could not have satisfied. I believe this is too quick. To see why, consider that according to Smith, while bartering makes things better for consumers and producers (the butcher can get bread, the farmer can procure metal tools), a market economy (with money and division of labor) allows everyone to benefit in a way that improves their situation relative to a barter-market. For instance, labor wages in such a market allow individuals to obtain a higher level of well-being (1776, especially Book 1). In addition, consider the idea of Paretoefficiency: the main appeal it offers is that in moving from an inefficient to an efficient distribution, we can improve the situation of at least some, while harming no one. Indeed, the fact that the market offers genuine, substantial improvements to people's well-being is often used to justify controversial practices, such as sweatshop employment or price gouging. ${ }^{31}$ Improving one's situation substantially plays an important role in justifying the market, in this sense.

What BDPP does is eliminate these advantages that the market offers. It takes consumers and places them back in a barter economy, in terms of their ability to enjoy what the market has to offer and, consequently, in terms of their well-being. In a BDPP market, everyone is maxed-out of their resources, just like participants in a barter economy. In a somewhat deontic spirit, the lesson here is that BDPP undermines the point of having a market in the first place, because it is a practice that cannot be universalized; if everyone did it, then we wouldn't have a market anymore - at least not in the way we normally think about and justify it.

When we consider this aspect of the market, it seems that BDPP does undermine individual welfare. In the circumstances described here, consumers can perhaps satisfy their preferences, but they cannot derive any additional, self-cultivating benefits from the market. This is very much in line with Heath's (2014) approach, according to which a practice is morally impermissible when and because it goes against the point of having a market. ${ }^{32}$ Indeed, one main advantage of MFA is that it helps us see that an efficient, competitive market is one in which consumers can substantially benefit. In a competitive market, firms compete with one another over consumer surplus in a race to the top, rather than a race to the bottom.

The unfairness that BDPP creates consists of stripping consumers of the ability to benefit from the market. BDPP undermines the status of consumers as participants in the market. It undermines their status as constitutive of how the market ought to work (i.e., through the price mechanism) and as sources for the value of the market. The point of having a market, we have seen, is to serve and benefit consumers.

\footnotetext{
${ }^{31}$ For instance, see Zwolinski (2007; 2008).

${ }^{32}$ I am happy to be on the same page with Heath on this. One important difference between my argument and Heath's is that my argument stands whether there is such an effect on consumer welfare or not, whereas Heath's seems to work only if there is such an effect.
} 
BDPP relies on and exacerbates existing information asymmetries in a way that undermines this very goal. BDPP is, therefore, an example of what MFA should regard as unethical. It helps us see how MFA can be refined and clarified: what is at stake in MFA is not the mere exploitation of market failures, nor is it simply reduced efficiency; rather, in taking up a Paretian approach to business ethics, what we should focus on is whether market failures are exploited and exacerbated, by way of undermining the ability of consumers to substantially benefit from participating in the market (as imperfect as it may be).

Interestingly, it follows from this that the unfairness inherent in BDPP connects back to the above discussion about relational equality. We have seen that a relational egalitarian approach places emphasis on there being equal social status and standing between citizens. In our context here, we can see that BDPP undermines this equality in two ways. First, as discussed above, BDPP leads firms to treat different consumers unequally: consumers have to compete with each other over prices but have no way of doing so fairly, and they will not be in a position to compete with firms either. More pointedly, BDPP undermines the value of consumers as participants in the market. It prioritizes firms and their interests over those of consumers in a way that undercuts the significance of consumers' role as sources of value in and of the market, and which undercuts the point of having markets in the first place. With BDPP, consumers lose their power to shape the market.

Information asymmetries abound even without BDPP. Their existence, as such, and their use by firms, need not necessarily be considered morally objectionable. The problem with BDPP has to do with whether consumers have reasonable means to overcome the relevant asymmetries. In an imperfect market without BDPP, consumers can — with reasonable effort - shop around and de facto negotiate over prices (by making use of market mechanisms). Once we introduce BDPP, consumers can no longer make use of the market-mechanism means that allow them to compete with firms by getting firms to compete for them. And this is unfair in a way that is unique to BDPP.

\section{CONCLUSION}

While BDPP is not currently available to firms, it is theoretically possible. I have argued in this article that BDPP holds some promise for better equality of welfare and resources. More precisely, while charging people the same amount for the same product is one way of treating them equally, charging them their reservation price allows us to treat them equally in terms of their welfare and their resources. BDPP also leads to better overall social welfare, especially in terms of improved efficiency in an imperfect market. In an imperfect market with market-powerful firms, BDPP allows such firms to serve previously unserved consumers. However, these advantages of BDPP are undermined when BDPP does not contribute to any socially desired end (other than improved market efficiency in an imperfect market). More specifically, when BDPP is used merely for the sake of profit maximization, this undermines the improvement to equality of welfare and resources by undercutting the relational equality among consumers, and between consumers and firms. 
When we consider that one important point of having competitive markets is to improve consumer welfare (rather than merely satisfy their preferences), we can use this notion of relational equality to reach a more refined version of MFA. According to this more refined version of MFA, firms should avoid taking part in practices that exploit and exacerbate market failures by way of undermining consumers' ability to benefit from the market. And we have seen that BDPP is an unethical business practice precisely because it exploits and exacerbates a market failure for the purpose of profit maximization by way of undermining the status and role of consumers in the market, and their ability to really benefit from it.

\section{ACKNOWLEDGEMENTS}

An earlier version of this article was presented at Ryerson University. I am grateful to the audience there for comments and discussions and to Daniele Bertolini for written comments on that version. I am also indebted to Chris MacDonald, Reut Marciano, and Hasko von Kriegstein for discussions and suggestions. Finally, I am extremely grateful to the editors and to two anonymous reviewers of Business Ethics Quarterly; their comments and feedback were constructive and helpful beyond all expectations, and significantly improved the quality of the article in its entirety.

\section{REFERENCES}

Anderson, Elizabeth S. 1999. "What Is the Point of Equality?” Ethics 109 (2): 287-337. Arneson, Richard J. 1989. "Equality and Equality of Opportunity for Welfare." Philosophical Studies 56 (1): 77-93.

Béranger, Jérôme. 2016. Big Data and Ethics: The Medical Datasphere. Amsterdam: Elsevier. Brown, Eric. 2013. "Vulnerability and the Basis of Business Ethics: From Fiduciary Duties to Professionalism.” Journal of Business Ethics 113 (3): 489-504.

Clerides, Sofronis K. 2002. "Book Value: Intertemporal Pricing and Quality Discrimination in the US Market for Books." International Journal of Industrial Organization 20 (10): $1385-1408$.

Clerides, Sofronis K. 2004. "Price Discrimination with Differentiated Products: Definition and Identification." Economic Inquiry 42 (3): 402-12.

Cohen, G. A. 1989. "On the Currency of Egalitarian Justice." Ethics 99 (4): 906-44.

Collmann, Jeff, and Sorin Adam Matei, eds. 2016. Ethical Reasoning in Big Data. New York: Springer International Publishing.

Duhigg, Charles. 2012. "How Companies Learn Your Secrets." The New York Times Magazine, February 16, 2012. https://www.nytimes.com/2012/02/19/magazine/shopping-habits. html.

Dworkin, Ronald. 1981a. "What Is Equality? Part 1: Equality of Welfare." Philosophy \& Public Affairs 10 (3): 185-246.

Dworkin, Ronald. 1981b. "What Is Equality? Part 2: Equality of Resources." Source: Philosophy \& Public Affairs 10 (4): 283-345.

Ekelund Jr., Robert B. 1970. "Price Discrimination and Product Differentiation in Economic Theory: An Early Analysis." The Quarterly Journal of Economics 84 (2): 268-278.

Elegido, Juan M. 2011. "The Ethics of Price Discrimination." Business Ethics Quarterly 21 (4): 633-660. 
Erwin, Sean. 2015. "Living by Algorithm: Smart Surveillance and the Society of Control." Humanities and Technology Review 34: 28-66.

Ezrachi, Ariel, and Maurice E. Stucke. 2016. Virtual Competition: The Promise and Perils of the Algorithm-Driven Economy. Cambridge, MA: Harvard University Press.

Galliott, Jai, and Warren Reed. 2016. Ethics and the Future of Spying : Technology, National Security and Intelligence Collection. London: Routledge.

Heath, Joseph. 2004. "A Market Failures Approach to Business Ethics." In The Invisible Hand and the Common Good, edited by Bernard Hodgson, 69-89. Berlin: Springer.

Heath, Joseph. 2006. "Business Ethics without Stakeholders.” Business Ethics Quarterly 16 (4): 533-57.

Heath, Joseph. 2014. Morality, Competition, and the Firm: The Market Failures Approach to Business Ethics. New York: Oxford University Press.

Krugman, Paul. 2000. "Reckonings; What Price Fairness?" The New York Times, October 4.

Lever, Annabelle. 2013. "Privacy, Democracy, and Security." The Philosophers' Magazine 63: 99-105.

Levine, Michael E. 2002. "Price Discrimination Without Market Power." Yale Journal on Regulation 19 (1): 1-36.

Lipsey, R. G., and Kelvin Lancaster. 1956. "The General Theory of Second Best." The Review of Economic Studies 24 (1): 11-32.

Marcoux, Alexei M. 2006. "Much Ado About Price Discrimination.” Journal of Markets \& Morality 9 (1): 57-69.

Marr, Bernard. 2017. "Really Big Data At Walmart: Real-Time Insights From Their 40+ Petabyte Data Cloud." Forbes, January 23.

Moriarty, Jeffrey. 2019. "On the Origin, Content, and Relevance of the Market Failures Approach.” Journal of Business Ethics, 1-12. doi: https://doi.org/10.1007/s10551019-04106-X.

Néron, Pierre-Yves. 2015. "Egalitarianism and Executive Compensation: A Relational Argument." Journal of Business Ethics 132 (1): 171-84.

Norman, Wayne. 2011. "Business Ethics as Self-Regulation: Why Principles That Ground Regulations Should Be Used to Ground Beyond-Compliance Norms as Well." Journal of Business Ethics 102 (1): 43-57.

Nozick, Robert. 1974. Anarchy, State, and Utopia. New York: Basic Books.

Odlyzko, Andrew. 2004. "Privacy, Economics, and Price Discrimination on the Internet." In Economics of Information Security, edited by L. Jean Camp and Stephen Lewis, 187-211. New York: Springer.

Paquette, Danielle. 2015. "Why You Should Always Buy the Men's Version of Almost Anything." The Washington Post, December 22.

Phlips, Louis. 1983. The Economics of Price Discrimination. Cambridge: Cambridge University Press.

Pigou, Arthur Cecil. 1920. The Economics of Welfare. London: MacMillan.

Robinson, Joan. 1933. The Economics of Imperfect Competition. Nw York: St. Martin's Press.

Sen, Amartya K. 1980. "Equality of What?" Tanner Lectures on Human Values, Volume 1, edited by S. McMurrin. Cambridge: Cambridge University Press.

Smith, Adam. 1776. An Inquiry into the Nature and Causes of the Wealth of Nations : A Selected Edition. Edited by Kathryn Sutherland. Oxford: Oxford University Press, 2008.

Stahl, Titus. 2016. "Indiscriminate Mass Surveillance and the Public Sphere." Ethics and Information Technology 18 (1): 33-39. 
Steinberg, Etye. 2017. "The Inapplicability of the Market-Failures Approach in a NonIdeal World." Business Ethics Journal Review 5 (5): 28-34.

Stigler, George Joseph. 1987. The Theory of Price. New York: Macmillan.

Stole, Lars A. 2007. "Price Discrimination and Competition." In Handbook of Industrial Organization, edited by Mark Armstrong and Robert H. Porter, 2221-2299. Amsterdam: North Holland/Elsevier.

Thaler, Richard H. 1999. "Mental Accounting Matters." Journal of Behavioral Decision Making 12 (3): 183-206.

Varian, Hal R. 1985. "Price Discrimination and Social Welfare." The American Economic Review 75 (4): 870-875.

Varian, Hal R. 1989. "Price Discrimination.” In Handbook of Industrial Organization, edited by Richard Schmalensee and Robert Willig, 597-654. Amsterdam: North Holland/ Elsevier.

von Kriegstein, Hasko. 2016. "Professionalism, Agency, and Market Failures.” Business Ethics Quarterly 26 (4): 445-464.

Zwolinski, Matt. 2007. “Sweatshops, Choice, and Exploitation.” Business Ethics Quarterly 17 (4): 689-727.

Zwolinski Matt. 2008. “The Ethics of Price Gouging." Business Ethics Quarterly 18 (3): 347-378.

ETye Steinberg is a PhD candidate at the department of philosophy at the University of Toronto. His main areas of research are philosophy of action and business ethics. He holds a BA in philosophy, economics, and political science and an MA in philosophy, both from the Hebrew University of Jerusalem. 